\title{
Casa do Pai, Casa da Mãe: A Coparentalidade após o Divórcio ${ }^{1}$
}

\author{
Luciana Suárez Grzybowski² \\ Universidade Comunitária da Região de Chapecó (UNOCHAPECÓ) \\ Adriana Wagner \\ Universidade Federal do Rio Grande do Sul
}

\begin{abstract}
RESUMO - A coparentalidade implica num interjogo de papéis que se relaciona com o cuidado global da criança, envolvendo responsabilidade conjunta dos pais pelo bem-estar desta. Foi realizado um estudo qualitativo com pais e com mães separados/ divorciados, enfocando a temática da educação e da coparentalidade após o divórcio. Os resultados apontaram para a importância das variáveis conjugalidade e vínculos pais-filhos no exercício da coparentalidade, sendo esta atravessada também pela coabitação, o sexo dos pais e filhos e as condições financeiras dos progenitores. Revelaram, também, pais mais participativos ou desejosos de participar na educação dos filhos, bem como mães mais satisfeitas com a guarda e menos culpadas com suas escolhas, comparados com outros relatos da literatura, evidenciando um novo cenário pós-divórcio.
\end{abstract}

Palavras-chave: coparentalidade; divórcio; conjugalidade; vínculos; família.

\section{Father's home, Mother's Home: Co-parenting after Divorce}

\begin{abstract}
Co-parenting implies an interplay of roles that is related to the child global care, and involves parents' joint responsibility for the child well being. It was carried a qualitative study with separated ldivorced fathers and mothers, focusing on the theme of education and co-parenting after divorce. The results pointed to the importance of connubial relations and parents-children bonds in the exercise of co-parenting. Moreover, co-parenting is also crossed over by cohabitation, parents and children's gender and the financial conditions of the progenitors. In this study, as compared to the literature, fathers were more participative or willing to participate in the education of their children, and mothers were more satisfied with the guard of their children and less guilty of their choices, thus demonstrating new post-divorce scenery.
\end{abstract}

Keywords: co-parenting; divorce; connubial relations; bonds; family.

O divórcio, há muito tempo, deixou de ser um fenômeno de exceção para tornar-se quase um acontecimento do cotidiano das famílias. Desde sua aprovação no Brasil, em 1977, o número de divórcios tem aumentado gradativamente, e cada vez mais casais buscam essa alternativa para solucionar a insatisfação conjugal (Grzybowski, 2007).

Entretanto, quando a separação envolve a existência de filhos da união, a questão se complexifica, e já não se trata apenas do fim de uma relação a dois que fracassou, mas também o início da relação de parentalidade de pais divorciados. Afinal, os filhos ainda precisarão de cuidados.

Falamos aqui em início da parentalidade, pois a parentalidade pós-divórcio parece ter diferenças significativas daquela exercida em conjunto na mesma casa, já que existe uma série de reformulações quanto aos hábitos, à rotina e ao padrão econômico da família. Além dessas mudanças que começam a acontecer, os membros do sistema familiar precisam adaptar-se a um aumento da complexidade no desempenho das tarefas desenvolvimentais. Dentre as diversas tarefas pós-divórcio, provavelmente a mais complexa fique ao encargo dos progenitores. Estes, recém-separados como

$1 \quad$ Este trabalho é parte integrante da Tese de Doutorado da primeira autora, defendida na PUCRS, em 2007, com apoio da CAPES.

2 Endereço para correspondência: Rua Mal. Floriano Peixoto, 545/105, Jardim Itália. Chapecó, SC. CEP 89801-500.E-mail: lugrzybowski@ unochapeco.edu.br. casal, permanecem unidos pelos laços parentais, devendo compartilhar a tarefa comum de educar os filhos (Carter \& McGoldrick, 1980/2001).

A literatura aponta que esta é uma das grandes dificuldades no divórcio: separar conjugalidade e parentalidade. A redefinição do envolvimento emocional dos dois indivíduos é um processo prolongado, que gera falhas nas fronteiras do relacionamento e conflitos pós-divórcio (Hackner, Wagner \& Grzybowski, 2006). Os papéis e regras parentais precisam ser (re)definidos, pois têm implicação direta na relação coparental. A parentalidade implica numa série de responsabilidades essenciais para com os filhos, tais como garantir a satisfação das necessidades econômicas e materiais, oferecer orientação e instrução, exercer autoridade, promover trocas afetivas e partilhar experiências do dia-a-dia (Thompson \& Laible, 1999).

O termo 'coparentalidade' (do inglês coparenting) foi introduzido por Bohannan na década de 70, referindo-se a aspectos do divórcio que se relacionam com os filhos (Ahrons, 1981). Recentemente, Madden-Derdich e Leonard (2002a) também definiram a coparentalidade como o nível de interação que os ex-cônjuges relatam ter um com o outro e como decidem questões da vida dos filhos. A coparentalidade trata-se, portanto, de um interjogo de papéis que se relaciona com o cuidado global da criança, incluindo valores, ideais, expectativas que são dirigidas à mesma, numa responsabilidade conjunta pelo bem-estar desta (Feinberg, 2002; Van Egeren \& Hawkins, 2004). 
Entretanto, isso não quer dizer que a coparentalidade exista apenas em situações de divórcio, pois ela está presente sempre que os pais, mesmo casados, negociam seus papéis, responsabilidades e contribuições para com seus filhos. A diferença é que, quando separados, os pais têm menos momentos e espaços em comum para efetivarem uma cooperação na educação dos filhos (Margolin, Gordis \& John, 2001). Porém, é importante ressaltar que o status marital (casado ou divorciado) é uma das variáveis relacionadas à qualidade da relação coparental, mas não é determinante da mesma, sendo que a coparentalidade pode até mesmo ser exercida por pessoas que não são um casal ou pais biológicos da criança (McHale, Kuersten-Hogan \& Rao, 2004; Talbot \& McHale, 2004; Van Egeren \& Hawkins, 2004).

Quando relacionamos coparentalidade e separação, observa-se que, de forma geral, muitos fatores presentes durante o casamento e na época do divórcio podem predizer a natureza da relação coparental em um momento posterior. Pesquisas realizadas em meados dos anos 90 afirmam que o grau de hostilidade que circunda o divórcio do casal tende a influenciar a relação pós-divórcio (Stewart, Copeland, Chester, Malley \& Barenbaum, 1997), evidenciando que o estado emocional dos pais tem impacto na relação posterior que eles estabelecem. Maccoby, Depner e Mnookin (1990), marcaram os estudos da coparentalidade ao apresentarem uma classificação sobre o relacionamento coparental:

- Padrão desengajado: os pais raramente conversam, não procuram manter uma combinação de regras ou atividades, educando os filhos de forma paralela. Eles têm pouco ou nenhum contato, o nível de conflito é baixo, pois cada um educa conforme o seu estilo;

- Padrão cooperativo: esses pais procuram isolar seus conflitos conjugais ou interpessoais de suas funções parentais. Discutem planos para os filhos ou problemas que estes possam estar enfrentando, procurando cooperar e apoiar o outro;

- Padrão conflitante: o nível de conflito é alto e ativo, existem baixos níveis de cooperação e prejuízos no domínio parental. Os pais discutem muito e utilizam-se de ameaças e boicotes envolvendo os filhos.

Os autores que propuseram tal classificação referem que os três tipos de padrão podem ser encontrados nas famílias em que os filhos moram com a mãe, com o pai ou ainda naquelas em que os pais têm guarda compartilhada, evidenciando que o padrão tende a ser independente do arranjo residencial (Maccoby \& cols., 1990).

Observa-se, então, a existência de três dimensões gerais da coparentalidade, que aparecem frequentemente na literatura (Maccoby \& cols., 1990; Margolin \& cols., 2001): quantidade ou nível de conflito em relação às questões parentais, cooperação (respeito, apoio e valorização) em relação ao outro progenitor e triangulação (aliança com os filhos para boicotar ou excluir o outro progenitor).

Após mais de uma década, Feinberg (2002) complementou o estudo de Maccoby e cols., (1990), apontando quatro componentes inter-relacionados necessários para configurar um modelo coparental. Nesse modelo são considerados: (a) o apoio versus a oposição no papel parental (afirmação, respeito, apoio às decisões e à autoridade parental); (b) as divergências em questões e valores que concernem à criação da criança (valores morais, prioridades, padrões educacionais); (c) a divisão de deveres, tarefas e responsabilidades relacionadas a rotinas diárias, cuidado infantil e tarefas domésticas; e (d) o manejo dos pais de aspectos interacionais da família (conflito, coalizões e equilíbrio). Esse modelo diferencia-se do anterior pois propõe uma divisão da dimensão cooperação em relação ao apoio parental, aos valores e à divisão de tarefas, mantendo a triangulação como manejo de aspectos interacionais.

Corroborando essas proposições, Van Egeren e Hawkins (2004) referem que existem quatro dimensões (ou tipos) de coparentalidade: (1) a coparentalidade solidária, caracterizada pela afetividade entre as figuras parentais, promovendo um crescimento conjunto da dupla e de uma execução parental unificada; (2) o apoio coparental, formado por estratégias e ações que potencializam os esforços dos parceiros para beneficiar a criança; (3) a coparentalidade destrutiva, na qual as estratégias e ações são no sentido de mitigar as tentativas do parceiro de atingir objetivos parentais, incluindo críticas e ausência de respeito; e (4) a parentalidade compartilhada, caracterizada pelo grau com que cada pai é responsável pela colocação de limites e pela justiça na divisão das responsabilidades.

Nesse sentido, identifica-se como preditores de uma boa relação coparental após o divórcio: a guarda compartilhada, os divórcios menos hostis, a satisfação com apoio financeiro e a existência de baixos níveis de conflitos entre os ex-cônjuges. Além desses aspectos, menor número de filhos e acordos sobre as visitas (Margolin \& cols., 2001; Struss, Pfeiffer, Preuss \& Felder, 2001), novo relacionamento amoroso que auxilie nas tarefas educativas ou libere o companheiro(a) para ter mais tempo com os filhos (Thomson, Mosley, Hanson \& Mclanahan, 2001), preocupação com ex-cônjuge e grau de amizade (Masheter, 1997), comunicação entre ex-cônjuges (Linker, Stolberg \& Green, 1999), percepção das habilidades parentais do ex-cônjuge, idade dos filhos e gênero do progenitor (Margolin \& cols., 2001) também são apontados como favorecedores da boa relação coparental.

Por outro lado, o fato de um dos ex-cônjuges ter recasado e ainda existir forte intensidade emocional em relação ao outro (Struss \& cols., 2001) e de haver divergências pré-divórcio sobre educação dos filhos (Madden-Derdich \& Leonard, 2002b) são indicativos de prejuízo para a coparentalidade. Também o fato de não ter ficado com a guarda é apontado como gerador de hostilidade pelo ex-cônjuge preterido, fazendo com que muitos se comuniquem por meio dos filhos ou evitem participar das tomadas de decisões em relação ao filho que não está sob sua guarda (Margolin \& cols., 2001).

A literatura refere que o ideal seria que, apesar do divórcio, ambos os pais continuassem assumindo funções educativas e participando de variadas atividades dos filhos, pois isto promove o bem-estar infantil. Mas, muitas vezes, o progenitor que não tem a guarda quer que suas visitas sejam divertidas e prazerosas, hesitando em criticar e monitorar o comportamento dos filhos, tendendo a ajudá-los menos 
em suas tarefas, do que pais casados (Struss \& cols., 2001; Wagner, 2002).

Após o divórcio, seria importante que pais e filhos renegociassem as fronteiras em sua relação, mantendo ou estabelecendo uma relação autorizante, combinando poder e intimidade. Porém, é comum que tanto os progenitores que têm a guarda como os que não têm, não consigam manter essa relação, em função da diminuição do tempo de convivência com os filhos, pelas suas questões emocionais e pelo conflito interparental. Os filhos passam menos tempo com um dos progenitores, ou talvez com os dois, e a afeição e o apoio que recebiam podem diminuir (Hilton \& Desrochers, 2000).

Dessa forma, o que se vê é que muitos pais e mães divorciados encontram dificuldades em manter um relacionamento coparental saudável. Somados a todas essas variáveis do contexto e da construção da coparentalidade, ainda existe a questão do envolvimento materno e paterno após a separação. Pois, para a própria definição do termo coparentalidade, independente da avaliação de sua qualidade, é necessária a presença de duas pessoas envolvidas e responsáveis pela educação dos filhos, e isto nem sempre ocorre.

Nesse sentido, observa-se que as mães são as mais frequentes detentoras da guarda após o divórcio (IBGE, 2006). Questiona-se se a guarda dos filhos é um privilégio materno ou mesmo uma consequência de uma visão difundida na sociedade e amparada por lei de que a ela compete a tarefa de educar os filhos (Wagner, 2002), acabando por sobrecarregála (Grzybowski, 2002). Por outro lado, enquanto alguns autores salientaram um crescimento nos níveis de ausência paterna, principalmente relacionado aos filhos nascidos fora do casamento e após o divórcio (Parke, 1996; Pleck, 1997), outros referem que muitos pais não residentes são capazes de manter uma relação próxima com os filhos, mantendo as funções paternas e até mesmo ficando responsáveis pela criação dos filhos e solicitando a guarda (Staudt, 2007; Wagner, 2002; Wallerstein \& Kelly (19801998).

Assim, percebe-se que a literatura, em geral, questiona o envolvimento parental masculino, uma vez que o feminino é esperado e consensual, até mesmo porque em termos factuais é à mãe que cabe a guarda das crianças. Diversas pesquisas vêm se ocupando de estudar o envolvimento paterno após o divórcio (Silva, 2003), identificando fatores que facilitam e dificultam a manutenção da relação entre pais e filhos. Alguns fatores têm sido apontados como favoráveis à manutenção do envolvimento paterno, entre os quais destacam-se: o relacionamento do pai com a criança e com a mãe; a satisfação com a paternidade; a percepção a respeito da influência que exerce na vida da criança; a percepção do valor da continuidade do seu envolvimento; o senso de responsabilidade como pai; a clareza quanto ao seu papel; a proximidade física; o plano de visitas regulares e rotineiras; a sociedade, cultura e grupo étnico do pai; o nível de escolaridade do pai e o encorajamento da ex-esposa ao relacionamento pai/filho (Amato \& Gilbreth, 1999; Erera, Minton, Pasley \& Mandel, 1999; Nielsen, 1999; Stone \& McKerny, 1998; Thompson \& Laible, 1999; Walker \& McGraw, 2000).

Entretanto, conforme Silva e Piccinini (2004), a maioria dos estudos que abordaram o envolvimento de pais não resi- dentes definiram o envolvimento paterno apenas em termos quantitativos, não distinguindo pais separados e pais nunca casados e avaliando o envolvimento apenas por meio das mães, sem consideração pela avaliação dos próprios pais.

Frente a isso, este estudo pretende dar voz aos pais e mães, para que possam falar de sua experiência enquanto pais divorciados, o que tem facilitado e dificultado esse processo e como exercitam a coparentalidade. Dessa forma, pretende-se contribuir para ampliar a compreensão que ambos têm sobre esse fenômeno multifacetado e extremamente atual na nossa sociedade, identificando as potencialidades e os entraves da coparentalidade pós-divórcio.

\section{Método}

\section{Participantes}

Participaram deste estudo 13 indivíduos, sendo seis pais e sete mães separados/divorciados, que integraram dois grupos focais de discussão da temática da educação e da coparentalidade pós-divórcio. O critério de agrupamento dos participantes foi a heterogeneidade de experiências pessoais em relação ao tema (tempo e tipo de separação, número de filhos, combinações de visitas, recasamento, apoio social, auxílio financeiro, qualidade da relação com o ex-cônjuge), identificada a partir de coleta de dados biodemográficos de outro estudo realizado (Grzybowski, 2007). Selecionou-se, de forma intencional, a partir daquele estudo com 234 participantes, pessoas com experiências diversificadas quanto à temática em questão.

Os grupos ficaram assim constituídos: no grupo de mães, as mulheres tinham entre 29 e 45 anos, estavam separadas há no mínimo 2 e no máximo 12 anos, tinham entre um e três filhos e todas tinham a guarda dos filhos, sendo que uma das mães tinha guarda compartilhada; três eram recasadas, quatro obtinham auxílio financeiro e três apresentavam conflitos com ex-cônjuge. No grupo de pais, os homens tinham entre 32 e 49 anos, estavam separados há no mínimo 3 e no máximo 15 anos, tinham entre um e três filhos e apenas um tinha a guarda dos filhos; quatro eram recasados, nenhum obtinha auxílio financeiro e três apresentavam conflitos com a ex-cônjuge.

\section{Instrumento}

Utilizou-se um roteiro-guia para condução das questões abordadas com os grupos. Tal roteiro baseou-se nos objetivos deste estudo e fundamentou-se na literatura pesquisada sobre o assunto, enfatizando os seguintes eixos: experiência parental após a separação; práticas educativas utilizadas por pais e mães divorciados; facilidades e dificuldades da educação do filho após o divórcio; avaliação do papel parental do ex-cônjuge; auto-avaliação no papel parental; exercício da coparentalidade após o divórcio; estratégias utilizadas diante da discordância das práticas educativas utilizadas pelo ex-cônjuge. 


\section{Procedimento}

Foram realizados dois grupos focais, selecionados conforme voluntariedade e heterogeneidade de experiências em relação à temática. Após diversas tratativas de data, local e horário, conseguiu-se realizar um grupo com 7 mães e outro com 6 pais. Os encontros foram realizados em dias distintos, com duração de 2 horas cada, utilizando-se de gravador e filmadora, com auxílio de um observador. Todos consentiram em participar da pesquisa e assinaram os Termos de Consentimento Livre e Esclarecido. Salienta-se, também, que a pesquisa foi avaliada e autorizada pelo Comitê de Ética em Pesquisa (CEP/PUCRS/Ofício 953/05).

\section{Análise de dados}

A condução dos grupos baseou-se nos postulados de Stewart e Shamdasani (1990) para a pesquisa com grupos focais. Após a conclusão da coleta de dados, fez-se a transcrição das falas e realizou-se uma análise de conteúdo segundo Olabuenága e Ispizua (1989). O diferencial nesse método de análise consiste em permitir ao pesquisador uma análise das categorias de forma horizontal (em cada grupo) e vertical (entre os grupos), o que se mostra convergente aos objetivos deste estudo. Buscando maior validade e fidedignidade da análise, a categorização foi discutida com três juízes (dois docentes de Psicologia e o observador dos grupos).

\section{Resultados}

Os resultados estão relacionados com os sete eixos de análise propostos para este estudo. Em cada eixo, emergiram categorias a partir dos conteúdos expressos nos grupos focais de pais e mães (análise vertical), sobre os quais teceu-se considerações específicas, buscando-se também comparar o conteúdo entre ambos os grupos (análise horizontal).

Conforme os depoimentos de pais e mães separados, a tarefa de educar um filho após o divórcio é complexa e multideterminada. Muitos são os fatores, intrínsecos e extrínsecos, que estão imbricados na dinâmica coparental após o rompimento do casamento (ver Diagrama 1).

Quanto à Experiência Educativa após o Divórcio (Eixo I), percebe-se que pais e mães pesquisados estão num processo de aprendizagem do exercício da coparentalidade pós-divórcio, pois mesmo considerando a 'experiência positiva', referem que estão constantemente avaliando e aprendendo com a prática: "é um desafio, pois se tu quiser tu pode passar por cima direto, ainda mais quando os filhos moram contigo, como é o meu caso. Tem que ter muito autocontrole, muita cabeça, não é fáci, mas tá sendo bom" (M- mãe).

As mães participantes demonstram maior 'sobrecarga' com a função parental pós-divórcio, principalmente relacionada à guarda e suas inevitáveis responsabilidades associadas: "olha, a mãe sempre é mais exigida com relação aos filhos, isso é um problema histórico, eu acho, mas depois da separação isso só aumentou. Me sinto super exigida, sugada, sobrecarregada. Muito mais que antes, agora sou eu pra tudo..." (M).

Já os pais, especialmente aqueles que não possuem a guarda dos filhos (que são a maioria neste estudo e na realidade brasileira), referiram que a experiência educativa pósdivórcio é marcada por 'perdas'. Para a maioria deles, sua função parental perdeu força e lugar, não conseguindo mais encontrar o espaço adequado para o seu desenvolvimento. A real distância gerada pelo afastamento do lar é sentida como uma 'ruptura no papel parental': “... eu sinto que perdi muita coisa com essa separação... meus filhos se afastaram, sei lá, não é mais a mesma coisa. Antes eles perguntavam a minha opinião, recorriam a mim pra decidir algo na vida deles, hoje eu só fico sabendo do resultado..." (P-Pai).

No que se refere às Práticas Educativas (Eixo II), observa-se que a guarda, apesar de sobrecarregar as mães deste estudo, é avaliada por elas como algo positivo para o estabelecimento das relações parentais, embora acabe tornando-as mais exigentes e controladoras ('controle') com seus filhos: "quem mora junto, claro, tem vantagens na educação dos filhos em relação a quem não convive, assim, todo dia, toda a hora, aquela rotina sabe. No fim das contas, é a gente que ensina mesmo, é o nosso jeito que predomina, as nossas manias, ordens, estilo de ser, não adianta” (M).

Porém, mesmo assim, elas consideram estar no rumo certo, uma vez que atrelada a essa disciplina conseguem conciliar o favorecimento da 'autonomia' dos mesmos. Percebe-se, aqui, que a sobrecarga no cuidado com os filhos é contrabalançada pela possibilidade de estar próxima deles e poder exercer mais intensamente o seu papel parental: "eu sei que eu sou a que puxa mais, então é mais chato ficar comigo, tão entendendo? Mas eu não me arrependo, não vou mudar a minha educação, eu acho que é pro bem dela, futuramente vai ser legal" (M).

Elas também referiram que sentem que ainda têm dificuldades de abordar alguns assuntos com os filhos do 'sexo' masculino, destacando questões de gênero, mesmo sempre buscando 'conversar' e 'estudar' para melhor orientar as crianças: "tem coisas que eu não consigo, eu não sei, tem que ser com o pai dele, eles são homens, se entendem melhor" (M).

Os pais participantes também evidenciaram dificuldades em conversar com os filhos do sexo feminino, assim como as mães relataram com relação aos filhos do sexo masculino. A questão do 'gênero do progenitor e do filho', ao que parece, ainda hoje determina as relações e as práticas educativas familiares. Isso também torna-se evidente quando os pais referem que têm dificuldade de conviver com filhos que são muito pequenos ('idade dos filhos'), em função dos cuidados que requerem, ou seja, ainda parece que os cuidados infantis precoces são exclusivos da mãe, e que o pai não tem capacidade para tal: "no início foi difícil, pois quando nos separamos as crianças tinham 3 e 5 anos e eu fui morar sozinho. Era bem complicado pegar elas pra passear, sair comigo, achava que não dava conta. Mas depois elas cresceram e eu me aproximei muito mais" (P).

Ao fazer uma Auto-avaliação no Papel Parental (Eixo $V$ ), a 'culpa' pela falta de tempo na convivência com os fi- 
Diagrama 1: Coparentalidade pós-divórcio.

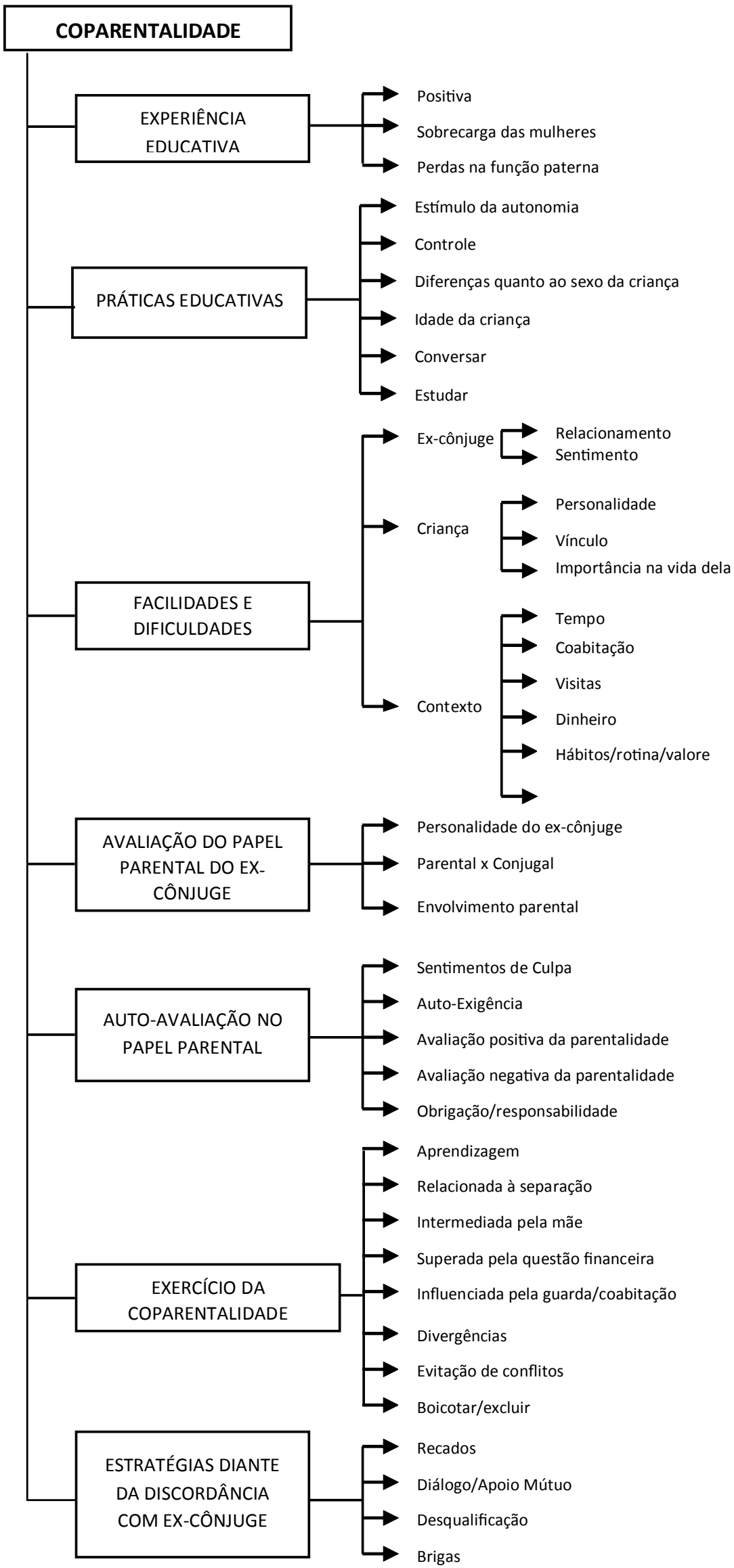


lhos foi constantemente apontada como um dificultador por pais e mães da pesquisa. As mães, apesar da sobrecarga com os filhos, têm um sentimento paradoxal de estar "fazendo pouco", o que evidencia também uma grande 'exigência' no exercício do papel parental. Já os pais sentem-se culpados na relação com os filhos pela falta de tempo com eles e porque acreditam que impuseram a realidade da separação aos mesmos. A diminuição da convivência produz sentimentos negativos nos pais, que conseguem avaliar que o tempo junto com os filhos é um problema de todas as famílias, sejam elas intactas ou não: "morar com a criança é importante, claro que é, mas não adianta morar e não estar junto. A gente não tem tempo pra curtir, pra aproveitar os filhos, e tem coisas que eles aprendem que não somos nós que ensinamos, o pai e a mãe, é a babá, é a vó, é a televisão... isso é um problema geral, não é só nosso que somos separados" (P).

Além disso, os pais/homens fazem uma 'avaliação negativa' de sua parentalidade, percebem-se distantes emocionalmente dos filhos e com pouca autoridade sob eles, o que denota que a distância nem sempre é apenas física, mas pode tornar-se emocional. Faz-se importante, no entanto, ressaltar que falamos aqui da percepção dos pais/homens, que parece estar "contaminada" por um sentimento de culpa que pode gerar uma visão mais pessimista do seu papel: "A gente se sente mal né, afinal, é por culpa nossa que eles não têm uma família igual as outras, eu não queria que fosse assim" (P)

É interessante salientar que as avaliações de pais (que não coabitam) e mães separados mesclaram aspectos positivos e negativos. Embora as mães se sintam sobrecarregadas e com algumas dificuldades, e os pais sintam que perderam seu espaço e têm pouco domínio sobre os filhos, ambos também avaliam que o divórcio trouxe mudanças positivas ao seu papel parental: "...ah, eu acho que melhorei, assim, melhorei como pai... antes eu não dava muita bola, ia levando. Mas agora eu tento aproveitar o máximo, quando estamos juntos eu quero ser melhor, eu mudei meu jeito, eu melhorei enquanto pai...” (P); “...não dá prá dizer que foi fácil, seria mentira né? Mas foi melhor assim, hoje me sinto bem, sei o que fazer, essa experiência toda me fortaleceu, sou uma mãe melhor que antes, agora eu cresci eu acho..." (M).

$\mathrm{O}$ único pai participante que coabita com suas filhas diferenciou-se dos demais pais e aproximou-se do perfil das mães. Ele faz uma 'autoavaliação positiva do seu papel parental', destacando o fato de estar conseguindo educar duas meninas sem a presença da mãe, o que para ele é um desafio. Nesse sentido, parece que a coabitação possibilita ao pai o exercício de uma parentalidade mais ampla e completa, na "brecha" que se abre quando a mãe sai de cena ou reduz sua participação. Isso faz questionar se o pai realmente não tem condições de exercer algumas funções ou se ele é ofuscado/ excluído, ou ainda deixa isso acontecer, pela presença da mãe: "eu tô satisfeito, no começo eu tinha medo, ficar com a guarda de duas meninas, mas tô me saindo muito bem” $(P)$.

Tanto os pais quanto as mães investigados apontaram um senso de 'responsabilidade' e uma 'obrigação' pela educação dos filhos. A ideia que circula no senso comum de que ser pai ou mãe (em especial) é uma questão altruísta e benevolente foi desconstruída pelos participantes da pesquisa, que evidenciaram que muitas tarefas educativas são realizadas sem prazer ou satisfação, mas apenas pela obrigação que se tem por alguém que depende deles para a sua manutenção e sobrevivência: "tem dias, muitas vezes, que a gente não quer nem ver, não tá a fim mesmo, se pudesse fazia desaparecer sabe? Mas a gente tem que cuidar, tem que ajudar, tem que vestir, dar comida, é obrigada né! Ninguém vai fazer e o filho é nosso, a gente que botou no mundo, tem que aguentar..."(M)

Os participantes também realizaram uma Avaliação do Papel Parental do Ex-Cônjuge (Eixo IV). Quanto aos fatores pessoais relacionados ao ex-cônjuge, observou-se que as características da 'personalidade do ex-companheiro(a)' podem facilitar ou dificultar a parentalidade, pois a personalidade se reflete na forma de ser pai ou mãe: "ela é uma mulher desleixada, desorganizada, confusa, e como mãe não poderia ser diferente" $(P)$. Essas características pessoais também tendem a interferir na avaliação recíproca interparental, que além de questões de personalidade, também é influenciada pela 'qualidade da relação conjugal e da separação do casal', bem como pelo 'envolvimento parental': "ele é um bom pai, sempre cumpre o combinado. Ás vezes chega até a me ligar nos dias que ela é minha pra ver se não pode ficar com ela, e se eu preciso de ajuda pra alguma coisa, sei lá, buscar, levar, ele tá sempre pronto" (M); "eu e o P. temos uma relação cordial, não dá prá dizer que somos amigos, eu nem queria manter essas coisas modernas da novela, de todo mundo junto reunido, mas a gente se respeita. Então, isso ajuda muito na educação das crianças” (M).

Todos os participantes também referiram muitos fatores processuais e contextuais que se relacionam com as Facilidades e Dificuldades do Exercício Coparental após $o$ Divórcio (Eixo III). Alguns fatores estão relacionados às 'características pessoais' de cada ex-cônjuge e às 'características da relação' estabelecida pelos ex-companheiros. Outros relacionam-se a questões do ‘contexto' e do processo no qual ocorre a dinâmica familiar. E há ainda alguns fatores relacionados às 'características das crianças' envolvidas no processo educativo e o seu papel na relação.

No que diz respeito às características da 'relação com o ex-cônjuge,' os 'conflitos' do casamento e as 'dificuldades' da separação têm relação direta com dificuldades na coparentalidade, assim como a existência de poucos conflitos e uma separação harmoniosa facilitam essa relação. Os sentimentos que o casal nutre um pelo outro também se refletem em facilidades ou dificuldades da relação. A intersecção do conjugal e do parental mostra-se evidente, tanto nas relações saudáveis quanto nas relações problemáticas: " $a$ h, eu acho que tem tudo a ver... a gente briga muito por causa das crianças, mas na verdade a gente briga porque a gente ainda tem muita coisa pra resolver, daí, tudo é motivo né, pra gente dizer pro outro aquilo que tá engasgado... na verdade eu ainda não aceito o que aconteceu..." (P).

Também as questões relacionadas ao contexto e ao processo familiar, como tempo com os filhos, coabitação, definição da guarda, combinações de visitas, hábitos e valores e o recasamento ou não dos pais, foram apontadas como facilitadoras ou dificultadoras do processo educativo.

Pais e mães deste estudo referiram que gostariam de passar mais 'tempo com seus filhos', acreditando que o pouco tempo é um fator negativo para a educação dos mesmos [“... falta tempo prá servir de modelo, e na falta de um, vai qual- 
quer um" $(P)]$. Entretanto, eles acrescentaram que o tempo disponível aos filhos é mais importante do que coabitar com eles, uma vez que a coabitação não garante a convivência de qualidade.

A avaliação da importância da 'coabitação' para a educação também esteve atrelada à experiência de cada progenitor, ou seja, tanto aqueles que coabitam quanto os que não coabitam a consideram uma variável fundamental, mas somente os que coabitam conseguiram criticar a coabitação. A crítica foi no sentido do papel que o progenitor que coabita acaba assumindo, de "chato" da dupla parental: "até pode ter essa vantagem aí, mas eu acho que os filhos às vezes enchem o saco de nós, pois o pai pega pra passear, prá sair, e a gente só cobra, todo dia, toda hora" (M). Por outro lado, aqueles que não coabitam (que nesta pesquisa eram pais) tendem a idealizar a coabitação como algo bem mais positivo do que as mães avaliam.

Apesar de considerarem a coabitação como algo positivo no sentido do desenvolvimento de 'hábitos, rotinas e valores da criança', as mães sentem seus esforços ameaçados pela convivência em outra casa que possui diferenças nesses aspectos. Referiram que isso prejudica sua tarefa educativa e pode servir de munição para os filhos manipularem seus pais: "Então eu acho que a dificuldade está aí, porque eu crio de um jeito e lá do outro lado eles não conseguem seguir esse meu jeito" (M).

Os pais, por outro lado, consideraram que os hábitos e rotinas divergentes são salutares para as crianças, como forma de experiência. Pode-se inferir que aqueles progenitores que coabitam (mães) sentem-se "donos" da educação dos filhos e parecem não querer perder esse lugar prioritário na vida deles. Já aqueles que não coabitam (pais) aprovam a rotina de troca de casas, o que seria aprovar a sua influência na constituição de hábitos e valores nos filhos, aprovar a sua participação.

Houve unanimidade entre os participantes quanto à importância da flexibilidade da regularidade das 'visitas' do progenitor não residente como fator facilitador da parentalidade pós-divórcio. Tal benefício é sentido pelo pai ou mãe e também pela criança, que conseguem se ver com mais frequência e estabelecer rotinas mais facilmente. Também a experiência de guarda compartilhada (relatada por uma mãe) foi muito elogiada pelo grupo de mães como uma alternativa saudável de coparentalidade, bem como uma forma de manter a relação parental "quase" como se fossem casados: “... então a gente não tem nada rígido, estipulado assim. Vai de acordo com a conveniência do $V$. (filho), e com a nossa." ( $P$ ). O esquema rígido de visitas foi considerado pelos participantes como algo relacionado à dificuldade dos pais de se encontrarem ou de conversarem, pois para os filhos, na sua opinião, a flexibilidade só tende a tazer benefícios.

Outra questão unânime nos grupos foi a 'colaboração que o novo(a) companheiro(a) traz para o exercício da parentalidade'. Pais e mães que recasaram ou têm uma união estável, relataram que esta pessoa trouxe muitas contribuições para a parentalidade por eles exercida, desempenhando papéis complementares aos seus. Não houve, entre os participantes, relato negativo quanto ao recasamento, parecendo que esses pais e mães estão conseguindo lidar melhor com essa experiência, tanto pessoal como do ex-companheiro: "eu acho que só veio a somar, ela me ajuda muito, assume coisas que eu não sei, não daria conta com as crianças” ( $P)$.

Quanto aos conflitos, a 'questão financeira' foi apontada como a causadora de muitos problemas. Segundo pais e mães desta pesquisa, é uma questão polêmica, e que sempre envolve insatisfação de ambos os lados, para quem dá e para quem recebe. Quem paga pensão, muitas vezes sente-se explorado, assim como quem recebe sente-se desvalorizado. Entretanto, tais sentimentos parecem estar mais atrelados à relação conjugal do que à parentalidade, uma vez que quem os relata são os ex-companheiros, um em relação ao outro: "ninguém nunca tá satisfeito: ou acha que o valor da pensão que tá recebendo é baixo, ou acha que o valor da pensão que tá pagando é alto" $(P)$.

Também as características dos filhos e da relação com eles estabelecida foram apontadas como envolvidas no processo coparental. Aqui também parece haver uma influência mútua entre o subsistema conjugal e o subsistema parental, como se um só pudesse funcionar bem se o outro também está bem, mesmo após a dissolução do casamento.

Pais e mães referiram que a criança é um 'personagem ativo' no processo educativo familiar, ou seja, ela não é apenas um receptor da educação fornecida pelos pais, mas aprende e constrói sua aprendizagem, especialmente na situação do divórcio, na qual ela experimenta algo diferente de outras famílias intactas, tendo que sintetizar a convivência com duas famílias. A sua 'personalidade' também pode facilitar ou dificultar a proximidade entre os pais e os filhos, pois o jeito como demonstram (ou não demonstram) o afeto pelo pai não residente pode aproximá-lo ou afastá-lo. Nesse sentido, parece que o senso de responsabilidade ou de obrigação, antes referido, é superado por questões relacionais, nas quais predomina a reciprocidade como geradora do 'vínculo parental', para além das questões de exigências pessoais: "eu sinto que tanto faz como tanto fez. Se eu ligo, eles falam comigo, mas se eu não ligo eles podem ficar a vida toda sem falar comigo. Então, comecei a me afastar, a me fechar, a me excluir do papel de pai" $(P)$.

Além desses aspectos, os pais referiram outras questões relacionais vinculadas a eles. Relataram que a manutenção da relação parental após o divórcio está muito atrelada aos 'sentimentos que nutriam pela ex-mulher' e à 'forma como esse(s) filho(s) surgiu no relacionamento' deles. $\mathrm{O}$ relacionamento com a "ex" teria, então, relação direta com o envolvimento ou o não-envolvimento parental após o divórcio, seja por ainda nutrirem sentimentos amorosos pela ex-companheira (as mães também referiram este aspecto), seja por nunca terem sentido amor pela ex-companheira ["eu só me casei com ela por pressão, por que ela engravidou. Eu nunca amei ela. Então, como vou amar um filho dela? Eu acho que é uma consequência, tu te afasta do filho, não te interessa mais por ele, por que o teu interesse era da situação, do momento, mas não um interesse de verdade, um amor de pai e filho" $(P)]$ ou mesmo por avaliarem que ela "teve" um filho seu sem seu consentimento e sem consequente vinculação com a criança [("... foi ela que quis, ela que engravidou sem combinar comigo, era desejo dela e não meu. Eu não queria ter sido pai, então, nunca consegui me envolver muito com eles, nem antes $e$ muito menos agora" (P)]. 
Novamente, aqui voltamos a um aspecto que se destacou nesses resultados: a influência do tipo de relação do casal e da separação conjugal no exercício da coparentalidade. Parece que apesar de, teoricamente, o subsistema conjugal ter se desfeito no divórcio, na prática, ele não se desfaz, apenas se transforma. Ele não existe mais no mesmo formato, mas parece vivo no exercício coparental pós-divórcio, influenciando permanentemente seus aspectos saudáveis ou problemáticos.

Além de apontarem as dificuldades e as facilidades de se educar um filho em casas separadas após o divórcio, os pais e mães desta pesquisa também relataram como tem sido para eles o Exercício da Coparentalidade (Eixo VI). Todos referiram que essa prática coparental após o divórcio é uma aprendizagem constante, que estão "aprendendo fazendo". A questão da 'separação conjugal' e da 'influência da coabitação' foram novamente levantadas nesse item, reforçando dois aspectos: a forma como se deu a separação pode facilitar ou até inviabilizar a coparentalidade, e a coabitação leva a práticas educativas individuais do progenitor que mora com a criança, mesmo que ele queira e valorize o exercício coparental. Nesse aspecto, aquele progenitor que tem a guarda (geralmente as mães) acaba exercendo mais práticas educativas de forma singular, o que pode ser visto como uma vantagem ou como uma sobrecarga, ou mesmo como uma mescla entre as duas avaliações, como ficou evidente entre os entrevistados. Porém, da perspectiva paterna, pode ser sentido como uma exclusão do papel parental: "por mais que eu não queira, tem coisas que eu acabo decidindo sozinha, não tem jeito. São coisas da hora, do momento, urgentes. Por exemplo, se vai ou não vai na aula, se pode ir numa amiguinha, se pode assistir um determinado programa na $T V$. Não teria como consultar ele" $(M)$.

Outra dificuldade relatada pelos grupos foi o "boicote ou exclusão do ex' da possibilidade de exercer seu papel parental, ficando de fora da coparentalidade, mesmo quando esse é desejoso de estar presente, o que foi observado em especial entre as mães. Tal fato é importante, pois além de demonstrar um egoísmo da função parental, pode estar revelando ressentimentos conjugais e até camuflando o verdadeiro motivo do não-envolvimento parental de um dos cônjuges, principalmente dos pais, tão criticados por se afastarem: "tem vezes que ele liga e o J. não ta, foi num amiguinho, e dai depois eu não dou o recado que o pai dele ligou" $(M)$.

Por outro lado, também existem mães deste estudo que já desistiram do exercício coparental ('desistência da coparentalidade') e resolveram assumir sozinhas a parentalidade a fim de 'evitar conflitos'. Essas mães referiram que cansaram de tentar, o que parece ser uma realidade, embora fosse importante conhecer a qualidade dessas tentativas e os motivos desse não envolvimento do ex-companheiro: "eu já me cansei, desisti mesmo, não adianta nada, ele não muda. Então, prá não dar problema, pros nossos filhos não sofrerem, eu não falo mais nada, não cobro mais, deixa assim, fica pra consciência dele decidir" (M).

Por fim, o poder feminino e o poder financeiro também demonstram sua força na parentalidade. As mães participantes relataram que elas "fazem" com que os pais se envolvam, 'indicando, exigindo ou delegando tarefas' relacionadas com os filhos. Nesse aspecto, parece que as mães estão menos passivas e mais exigentes com a participação dos pais, denotando que já não querem mais assumir sozinhas o cuidado dos filhos: "Mas também nos finais de semana eu me imponho assim, no final de semana que ela vai ficar com ele, tem temas, tem a agenda. E se tem reuniões na escola, naquele final de semana que ela tá com ele, a reunião é prá ele, eu não vou" (M).

Entretanto, algumas decisões que poderiam ser consensuais, tornam-se unilaterais, conforme o 'poderio financeiro dos ex-cônjuges'. Pais e mães estudados referiram que manda mais quem paga mais, evidenciando que a questão financeira supera toda e qualquer relação coparental, saudável ou não: “..em relação a outras coisas como troca de colégio, sou eu quem decido, eu não pergunto nada prá ele, eu apenas o comunico: "olha eu tô trocando, eu já fui à escola, fui ver e vou trocar". Porque tem coisas que eu tenho que tomar as rédeas, afinal fazem seis meses que eu arco com tudo financeiramente." $(M)$.

Dificuldades também podem ocorrer quando um excônjuge diverge fortemente da conduta educativa do outro ('divergências'), havendo a necessidade de encontrar Estratégias diante das Discordâncias com o Ex-Cônjuge (Eixo VII). Podem haver 'brigas' ["é muita briga, é só briga, não tem conversa. A gente tá sempre brigando prá ver quem vai fazer o que, o que cada um tem que fazer e o que cada um deixou de fazer" (P)], 'desqualificações' [ "semana passada ela me ligou me cobrando, que o nosso filho tinha contado que eu tinha dito que ela era relaxada, desorganizada. Daí eu vi que tinha falado demais na frente dele, falado mal da mãe dele" $(P)]$, e até mesmo "uso" dos filhos para envio de 'recados' ao ex-cônjuge criticado [ “... eu digo mesmo, digo prá M. dizer pro pai dela que não é assim, dizer prá ele que eu não gostei" $(M)$ ]

Essas divergências prejudicam o exercício da coparentalidade, e já não há planejamento do futuro do filho e pouca ou nenhuma divisão de tarefas em relação aos cuidados deste. A triangulação com a criança é prejudicial para o desenvolvimento infantil e acaba colocando o filho num papel que não lhe caberia: "esses dias ele foi lá prá casa sem fazer os temas, dai eu disse prá ele dizer prá mãe dele que eu não tinha gostado disso e que não era mais prá acontecer" $(P)$

Mas nem todas as experiências relatadas pelos participantes são marcadas por aspectos negativos. Muitos pais e mães referiram que conseguem ter um exercício coparental baseado no 'apoio mútuo', superando as divergências com 'diálogo' aberto sobre as diferenças e buscando alternativas para solucioná-las, visando o bem-estar último do(s) filho(s). Entre esses, foi unânime a qualidade da relação conjugal que haviam estabelecido e a forma harmoniosa do fim do casamento, evidenciando o peso dessas variáveis: "Eu e o A., a gente vê mais ou menos como se faz, como a gente está sempre se vendo, a gente conversa sobre ela. A gente vai prás festas e fica falando da nossa filha, até as vezes eu digo "sai daqui, vamos curtir e parar de falar disso" (risos). E eu falo muito com ele sobre essas questões assim, de como vai ser, se tem que fazer desse jeito" (M); "teve um problema com ele na escola e eu fiquei mal, eu liguei pro pai dele e falei tudo o que estava acontecendo. E a gente tentou conversar com a coordenadora, ele foi comigo prá me apoiar e me proteger" (M) 


\section{Discussão}

São muitas as relações que se estabelecem entre os fatores envolvidos na coparentalidade capazes de explicar tal fenômeno, desde questões individuais, relacionais, contextuais e processuais, que coexistem numa dinâmica de interdependência. Porém, duas questões parecem marcar profundamente o exercício da coparentalidade pós-divórcio, perpassando todas as demais: a conjugalidade e os vínculos emocionais pais-filhos. Daí parecem decorrer todas as outras questões envolvidas no processo coparental.

O vínculo que uniu o casal, os sentimentos que nutriam ou ainda nutrem um pelo outro, a forma como se deu a separação e a superação ou não das problemáticas emocionais conjugais, se mostram atreladas à forma como se dá a coparentalidade. Se não houve um vínculo importante entre o marido e a mulher, se os filhos não foram fruto de uma escolha mútua, se a separação foi conflituosa ou não consensual e/ou se um dos ex-cônjuges ainda tem forte vínculo afetivo-sexual pelo outro, é muito provável que haja um afastamento parental ou um exercício coparental problemático. A conjugalidade está imbricada na parentalidade, são indissociáveis, mesmo após o fim do casamento (Hackner \& cols., 2006).

Os elos de ligação entre pais e filhos, antes e depois do fim do casamento, parecem também determinar a coparentalidade. Tal aspecto mostrou-se relevante na relação do pai com os filhos, parecendo que às mães esse vínculo é natural. As mães não relataram isso como determinante de sua parentalidade, reforçando a ideia de que esse vínculo mãe-filho é inerente. Entretanto, como a coparentalidade é o exercício de duas pessoas, o fato de os pais referirem isso deve ser considerado. Os pais/homens justificam a proximidade ou o afastamento dos filhos em função do sentimento que têm por eles e da sensação de reciprocidade dos mesmos. Filhos não desejados ou que não demonstram a falta dos pais são filhos que têm maior chance de verem seus pais se afastarem, mesmo os pais relatando um senso de responsabilidade por seus filhos. As mães parecem não ter essa opção (pelo menos na maioria das vezes, em função da guarda materna), embora consigam demonstrar que nem sempre mantêm o envolvimento parental por puro prazer ou escolha.

A coabitação também mostrou-se fortemente relacionada à forma da coparentalidade. As mães têm mais práticas educativas individuais do que os pais por morarem com os filhos, bem como mais envolvimento direto com eles em função disso. Os pais evidenciam maior envolvimento indireto com os filhos em função de não coabitarem com eles. A coabitação leva, invariavelmente, a maior envolvimento parental direto, embora não exclua o desenvolvimento de uma coparentalidade saudável, ou seja, não é porque a mãe toma sozinha algumas atitudes em relação ao filho, que ela deixe de valorizar ou de exercer uma coparentalidade com o ex-companheiro (Margolin \& cols., 2001; Van Egeren \& Hawkins, 2004). Por outro lado, a coabitação não pareceu ser um fator apenas positivo. Ela traz sobrecarga, exigência parental e desafios maiores ao progenitor na educação dos filhos, embora permaneça idealizada por aquele progenitor que não detém a guarda do filho.

Dessas questões vão derivar uma coparentalidade solidária e compartilhada (com apoio mútuo, planejamento do futuro dos filhos, cooperação, respeito, valorização, divisão de tarefas, foco no bem-estar dos filhos) ou uma coparentalidade destrutiva e conflitante (sem cooperação, conflituada, triangulada com os filhos - boicote, exclusão -, permeada por críticas, desrespeito, brigas, e sem divisão de tarefas e responsabilidades) ou, ainda, uma coparentalidade inexistente ou desengajada (cada um educa ao seu estilo, com pouco ou nenhum contato).

Questões como acordos financeiros, regulação de visitas, práticas educativas, são influenciadas pelas três variáveis inicialmente citadas (coabitação, conjugalidade, vínculos paisfilhos), bem como pelo gênero e poder financeiro do progenitor e pela personalidade e gênero da criança, revelando a interdependência de tais variáveis e do contexto no qual se inserem.

As mães demonstraram que não são "vítimas" do divórcio, não evidenciando descontentamento pelas consequências do mesmo e buscando envolver o ex nas responsabilidades com os filhos. Além disso, os resultados evidenciaram que ter a guarda pode ser uma satisfação e não apenas uma sobrecarga, pois há um certo "prazer" em ter o domínio e controle maior dos filhos, tendo práticas educativas independentes e rejeitando as experiências educativas da casa dos pais.

Cabe destacar que algumas mulheres participantes que não recebem pensão ou que ganham mais que os ex-maridos demonstraram um perfil diferenciado de separadas/divorciadas, evidenciando mais autonomia, inclusive na parentalidade. A união entre coabitação e supremacia financeira parece indicar uma mulher "poderosa", no sentido do controle e educação dos filhos. Porém, talvez aquelas que têm uma dependência financeira (o que talvez represente a maior parte) tenham que aceitar decisões que não concordam e talvez aceitar práticas, mesmo discordando delas.

Os pais não residentes, apesar de fazerem uma avaliação geral mais negativa de seu papel parental após o divórcio, mostraram-se participativos ou desejosos de serem mais participativos (Silva, 2003; Wagner, 2002), com exceção daqueles emaranhados em algumas das dificuldades apontadas inicialmente (conjugalidade e vínculo parental). Da mesma forma, a avaliação que as mães fizeram dos ex-maridos aponta nessa direção, corroborando a ideia de uma visão dos pais divorciados mais positiva.

Em termos de avaliação do ex, as mulheres/mães mostraram-se bem menos críticas em relação aos homens/pais do que o contrário, assim como elas foram mais positivas em relação a si próprias do que eles. Tais constatações levam a pensar numa possível dificuldade materna de autoavaliação (crítica) ou num contentamento com sua situação, bem como numa melhora da participação dos pais que leva a menos críticas das mães, ou ainda numa indiferença e exclusão dos mesmos da coparentalidade. Também poderíamos pensar na naturalização do papel materno, que leva a produção de poucas ou nenhuma crítica sobre seu papel, considerado inerente à mulher tal exercício. Por parte dos pais, pode-se pensar numa autocrítica severa motivada pela culpa que referiram sentir, ou num processo construtivo de autorreflexão e busca de melhorias na sua função parental. Além disso, suas críticas à mulher podem ser motivadas por questões conjugais mal resolvidas, avaliação de fraco desempenho parental ou sentimento de exclusão da parentalidade por elas (Feinberg, 2002). 
Diante disso, os resultados levantam o questionamento a respeito de questões de gênero parentais. As mães, muitas vezes consideradas "vítimas do divórcio", talvez não o sejam. E os pais, tantas vezes considerados "vilões do divórcio", talvez também não o sejam. Aliás, neste estudo, os pais se mostraram, muitas vezes, mais vitimizados do que as mães, invertendo o cenário difundido pós-divórcio. Assim, parece que algumas combinações de variáveis diferentes configuram um cenário cambiável, que parece alternar posições entre pais e mães após o divórcio. Esse processo é circular, no qual a postura de um tem reflexos sobre a conduta do outro e vice-versa, fazendo com que existam diferentes tipos de pais e mães, bem como diferentes tipos de coparentalidade após o divórcio.

Dessa forma, os resultados apontam para a conjugalidade e o vínculo parental como variáveis preditoras da qualidade da coparentalidade, tendo como variáveis interligadas principais a coabitação, o gênero e a questão financeira dos progenitores. Tais questões tendem a interferir na qualidade da relação coparental, regulando as combinações educativas, as visitas e os cuidados. A indissociabilidade do subsistema conjugal do parental, e a interdependência entre eles, apontam para uma questão central: o envolvimento parental relaciona-se ao envolvimento conjugal, não sendo possível investir apenas na manutenção da relação pais-filhos sem um investimento na resolução e modificação da relação do par conjugal/parental. Ou seja, qualquer tentativa de qualificar ou potencializar a relação pais e filhos após o divórcio deve levar à reflexão e posterior elaboração/resolução da relação e separação conjugal.

\section{Referências}

Ahrons, C. R. (1981). The continuing coparental relationship between divorced spouses. American Orthopsychiatric Association, 51, 415-428.

Amato, P. R., \& Gilbreth, J. G. (1999). Nonresident fathers and children's well-being: A meta-analysis. Journal of Marriage and the Family, 61, 557-573.

Carter, E., \& McGoldrick, M. (2001). As mudanças no ciclo de vida familiar: uma estrutura para terapia familiar. Porto Alegre: Artes Médicas. (Trabalho original publicado em 1980)

Erera, P., Minton, C., Pasley, K., \& Mandel, S. (1999). Fathering after divorce in Israel and U.S. Journal of Divorce \& Remarriage, $31,55-82$.

Feinberg, M. E. (2002). Coparenting and the transition to parenthood: A framework for prevention. Clinical Child and Family Psychology Review, 5, 173-195.

Grzybowski, L. S. (2002). Famílias monoparentais: mulheres divorciadas chefes de família. Em A. Wagner (Org.), Família em cena: tramas, dramas e transformações (pp. 39-53). Rio de Janeiro: Vozes.

Grzybowski, L. S. (2007). O envolvimento parental após a separação/divórcio. Porto Alegre: PUCRS.

Hackner, I., Wagner, A., \& Grzybowski, L. S. (2006). A manutenção da parentalidade frente à ruptura da conjugalidade. Pensando Famílias, 10, 73-86.

Hilton, J., \& Desrochers, S. (2000). The influence of economic strain, coping with roles and parenting of custodial single mothers and custodial single fathers. Journal of Divorce and Remarriage, 33, 1-19.
Fundação Instituto Brasileiro de Geografia e Estatística - IBGE (2006). Estatísticas do registro civil. Rio de Janeiro: IBGE.

Linker, F., Stolberg, A., \& Green, R. (1999). Family communication as a mediator of child adjustment to divorce. Journal of Divorce and Remarriage, 30, 83-97.

Maccoby, E., Depner, C., \& Mnookin, R. (1990). Coparenting in the second year after divorce. Journal of Marriage and the Family, 52, 141-155.

Madden-Derdich, D., \& Leonard, S. (2002a). Parental role identity and father's involvement in coparental interaction after divorce: Father's perspectives. Family Relations, 49, 311-318.

Madden-Derdich, D., \& Leonard, S. (2002b). Shared experiences, unique realities: Formerly married mother's and father's perceptions of parenting and custody after divorce. Family Relations, 51, 37-45.

Margolin, G., Gordis, E., \& John, R. (2001). Coparenting: A link between marital conflict and parenting in two-parent families. Journal of Family Psychology, 15, 3-21

Masheter, C. (1997). Healthy and unhealthy friendship and hostility between ex-spouses. Journal of Marriage and the Family, 59, 463-475.

McHale, J. P., Kuersten-Hogan, R., \& Rao, N. (2004). Growings points for coparenting theory and research. Journal of Adult Development, 11, 221-234.

Nielsen, L. (1999). Demeaning, demoralizing and disenfranchising divorced dads: A review of the literature. Journal of Divorce \& Remarriage, 31, 139-177.

Olabuénaga, J. I. R., \& Ispizua, M. A. (1989). La descodificación de la vida cotidiana: Métodos de investigación cualitativa. Bilbao: Universidade de Densto.

Parke, R. D. (1996). Fatherhood. Cambridge: Harvard University.

Pleck, J. H. (1997). Paternal involvement: Levels, sources, and consequences. Em M. Lamb. (Org.), The role of the father in child development (pp. 89-105). New York: John Wiley \& Sons.

Silva, M. R. (2003). Sentimentos sobre a paternidade e envolvimento paterno de pais que residem e pais que não-residem com seus filhos. Dissertação de Mestrado, Pontifícia Universidade do Rio Grande do Sul, Porto Alegre.

Silva, M. R., \& Piccinini, C. A. (2004). O envolvimento paterno em pais não-residentes: algumas questões teóricas. Psico, 35, 185-194.

Staudt, A. C. P. (2007). Paternidade em tempos de mudança: uma reflexão sobre a contemporaneidade. Dissertação de Mestrado, Pontifícia Universidade do Rio Grande do Sul, Porto Alegre.

Stewart, M., Copeland, A., Chester, N., Malley, J., \& Barenbaum, N. (1997). Separating together: How divorce transforms families. Nova York: Guiford Press.

Stewart, D., \& Shamdasani, P. (1990). Focus groups: Theory and practice. Newbury Park, CA: SAGE.

Stone, G., \& McKenry, P. (1998). Nonresidential father involvement: A test of a mid-range theory. The Journal of Genetic Psychology, 159, 313-336.

Struss, M., Pfeiffer, C. Preuss, U., \& Felder, W. (2001). Adolescents from divorced families and their perceptions of visitations arrangements and factors influencing parent-child contact. Journal of Divorce and Remarriage, 35, 75-89.

Talbot, J. A., \& McHale, J. P. (2004). Individual parental adjustment moderates the relationship between marital and coparenting quality. Journal of Adult Development, 11, 191-205. 
Thompson, R. S., \& Laible, D. J. (1999). Noncustodial Parents. Em M. Lamb (Org.), Parenting and chil development in "nontradicional" families (pp. 103-123). New Jersey: Lawrence Eribaum.

Thomson, E., Mosley, J., Hanson,T., \& McLanahan, S. (2001). Remarriage, cohabition and changes in mothering behavior. Journal of Marriage and Family, 63, 370-380.

Van Egeren, L. A., \& Hawkins, D. P. (2004). Coming to terms with coparenting: Implications of definition and measurement. Journal of Adult Development, 11, 165-178.

Wagner, A. (2002). Possibilidades e potencialidades da família: a construção de novos arranjos a partir do recasamento. Em A. Wagner (Org.), Família em cena: tramas, dramas e transformações (pp. 23-38). Petrópolis: Vozes.
Walker, A., \& McGraw, L. (2000). Who is responsible for responsible fathering? Journal of Marriage and the Family, 62, 563-569.

Wallerstein, J., \& Kelly, J. (1998). Sobrevivendo à separação: como pais e filhos lidam com o divórcio (M. A. V. Veronese, Trad.). Porto Alegre: Artes Médicas. (Trabalho original publicado em 1980)

Recebido em 13.08.08

Primeira decisão editorial em 20.07.09

Versão final em 17.08.09

Aceito em 20.08.09 